\title{
Sexual Power and HIV Risk, South Africa
}

\author{
Audrey E. Pettifor, ${ }^{*}$ Diana M. Measham, †‡ Helen V. Rees, ${ }^{*}$ and Nancy S. Padian $\ddagger$
}

Gender power inequities are believed to play a key role in the HIV epidemic through their effects on women's power in sexual relationships. We hypothesized that lack of sexual power, measured with a four-point relationship control scale and by a woman's experience of forced sex with her most recent partner, would decrease the likelihood of consistent condom use and increase the risk for HIV infection among sexually experienced, 15- to 24-year-old women in South Africa. While limited sexual power was not directly associated with HIV, it was associated with inconsistent condom use: women with low relationship control were 2.10 times more likely to use condoms inconsistently (95\% confidence interval [Cl] 1.17-3.78), and women experiencing forced sex were 5.77 times more likely to inconsistently use condoms (95\% Cl 1.86-17.91). Inconsistent condom use was, in turn, significantly associated with $\mathrm{HIV}$ infection (adjusted odds ratio $1.58,95 \% \mathrm{Cl}$ 1.10-2.27).

$\mathrm{I}^{\mathrm{n}}$ 2002, the prevalence of HIV infection among South African women attending antenatal clinics was $26.5 \%$ (1). Among all 15- to 24 -year-olds, $12 \%$ of women were infected, compared with $6 \%$ of men (2). While women's greater biological susceptibility to HIV helps explain this difference, a host of sociocultural and economic factors rooted in gender power inequities exacerbate women's vulnerability to infection.

Gender power inequities play a key role in the HIV epidemic through their effects on sexual relationships (3-5). In South Africa, multiple partnerships are condoned and even encouraged for men, while women are expected to be monogamous and unquestioning of their partner's behavior (5-7). Sexual refusal or negotiation may result in suspicions of infidelity and carry the risk of violent outcomes $(8,9)$. Younger women are likely to be at a particular disadvantage, as documented by a growing body of qualitative research $(6,8,10)$. A study of youth in a Xhosa township,

\footnotetext{
*University of the Witwatersrand, Johannesburg, South Africa; †University of California at Berkeley, Berkeley, California, USA; and $\ddagger$ University of California at San Francisco, San Francisco, California, USA
}

for example, showed "pervasive male control over almost every aspect of [women's] early sexual experiences," enacted in part through violent and coercive sexual practices (8).

A host of economic vulnerabilities underlies young women's inability to challenge the sexual status quo. In the context of poverty, young women speak of money as the driving force for sex and relationship formation $(9,11)$. Partnerships with men who can provide financially are essential, transactional relationships (in which sex is exchanged for material goods or other support) are common, and relationships with older men are the norm $(12,13)$.

Several studies in the region have found that women's status or household power has effects on general contraceptive use (14-18). Very few studies have focused on younger women, attempted to measure relationship power directly, or assessed its effects on HIV-preventive behaviors. One exploratory study in Botswana found that negotiating power explained $47 \%$ of the variance in condom use (19). A study in Uganda had more mixed results, finding that relative control over sex and fertility had variable effects on condom use, depending on which partner's reports were used, and whether partner reports were in conflict (20).

A larger body of research exists on relationship power and HIV-preventive practices in the developed world, primarily among ethnic minorities in the United States. These studies have used a range of measures in their efforts to quantify relationship power, and some have had null or inconclusive results (21-23). A few studies have documented important effects, finding that women with greater sexual relationship power are more likely to use condoms or to use condoms consistently $(24,25)$.

We undertook a preliminary exploration of the effects of sexual power on both HIV serostatus and condom use consistency by using data collected from a nationally representative sample of sexually experienced young women, 15-24 years of age, in South Africa. While investigating sexual power was not the primary aim of the survey, a set of questions on related issues was included. 


\section{Methods}

\section{Sample}

In 2003, data on sexual power, HIV risk behaviors, and HIV serostatus were collected during a nationally representative household survey of men and women 15-24 years of age. Participants were selected thorough stratified, disproportionate, systematic sampling in the country's nine provinces. A total of 11,904 interviews were completed, including 4,066 with sexually experienced young women, the subsample used in this analysis. Additional details on the survey's methods are described elsewhere (26).

Informed consent was obtained from all participants, and parental consent was obtained for those 15-17 years of age. The study was approved by the Committee for the Protection of Human Subjects, University of the Witwatersrand, Johannesburg, South Africa.

\section{Measurement Tools}

Participants completed an interviewer-administered questionnaire that covered sociodemographic factors, HIV risk behavior, and sexual power. All questions were translated from English into Sotho, Zulu, Tswana, Xhosa, Pedi, Venda, Tsonga, and Afrikaans, and then back-translated. Participants were anonymously tested for HIV by using the Orasure Oral Specimen Collection Device (Orasure Technologies Inc, Bethlehem, PA). The specimens were tested for HIV-1/2 antibodies by using the Vironostika Uni-Form II HIV-1/2 plus O MicroElisa System (Biomerieux, Durham, NC).

\section{Measures}

Our primary outcome variables of interest were HIV serostatus and condom use consistency. Women who always used condoms with their most recent partner in the past 12 months were categorized as consistent condom users; never or occasional use was categorized as inconsistent use.

Sexual power was measured through two factors: relationship control and recent experience of forced sex. Four questions were used to construct the relationship control scale, and these were drawn in part from the Sexual Relationship Power Scale (SRPS) (27), which contains 23 items in two subscales (decision-making dominance and relationship control). A pilot test of the full scale was conducted, questions were revised, and several were eliminated due to difficulties in translating concepts, lack of comprehension among pilot test participants, and space constraints in the questionnaire. Five questions remained after this process and were examined in SPSS (SPSS Inc., Chicago, IL) by using factor analysis, which verified that four of the five questions created one factor. The four questions retained, all of which required an agree or disagree response, were as follows: your partner has more control than you do in important decisions that affect your relationship; when you and your partner have an argument, your partner gets his way most of the time; your partner has more control than you do over whether or not you use condoms; your partner has more control than you do over whether or not you have sex. Reliability analysis confirmed moderate internal consistency (Cronbach's alpha 0.69). We dichotomized the four-point scale for analytic purposes, with a score of $0-2$ indicating high relationship control and 3-4 indicating low control. Forced sex was measured by asking each woman if her most recent sexual partner in the past 12 months ever physically forced her to have sex (yes or no).

In addition to the sexual power variables, we examined other participant characteristics and sexual practices that have been hypothesized to effect condom use consistency and HIV status or which might confound relationships of primary interest. These variables are presented in Table 1. In particular, an index to measure condom use selfefficacy was created by using the following questions, each of which required a yes or no answer: Would you be able to use a condom every time you have sexual intercourse? Would you be able to refuse to have sex if your partner would not use a condom? Would you be able to talk about using condoms with your partner? The index had moderate internal consistency (Cronbach's alpha $=0.60$ ).

\section{Analysis}

The final sample was weighted to represent the distribution of young people 15-24 years of age based on the 2001 census, with a particular focus on ensuring representativeness based on sex, age, race, province, and rural or urban residence. Analyses were conducted in STATA 7.0 (STATA Corp, College Station, TX) by using svy methods and adjusting for sample strata, primary sampling units, and population weights.

Chi-square tests for categorical variables and $t$ tests for continuous variables were conducted to test for differences in HIV serostatus and condom use consistency by sexual power, HIV risk behavior, and sociodemographic factors. Variables were selected for the logistic regression models based on both a priori hypotheses and empiric findings. We hypothesized that relationship control and forced sex would primarily be associated with HIV indirectly through their effects on condom use, but that they could also be associated indirectly with HIV infection through other mechanisms, such as higher risk sexual practices (e.g., anal sex) or elements of unprotected intercourse not captured through the condom use consistency variable. Hence, we examined both the relationship between sexual power and condom use consistency and that between sexual power and HIV status. 
Table 1. Weighted frequencies of HIV prevalence, sexual power, sociodemographic factors, and HIV risk behavior among sexually experienced women 15-24 years of age, South Africa, 2003

\begin{tabular}{|c|c|}
\hline Characteristic & Weighted frequency $(\%)$ \\
\hline HIV positive & 21.1 \\
\hline Low relationship control with current partner & 26.6 \\
\hline Did not always use a condom with last partner in past 12 mo & 71.4 \\
\hline$>1$ Lifetime sexual partner & 54.6 \\
\hline$>1$ partner in the past $12 \mathrm{mo}$ & 12.8 \\
\hline Most recent sexual partner in past 12 mo was a regular partner & 98.2 \\
\hline Most recent partner in past 12 mo physically forced to have sex & 3.8 \\
\hline Ever been physically forced to have sex in lifetime & 9.6 \\
\hline Transactional sex with most recent partner in past 12 mo & 1.3 \\
\hline Most recent partner in past $12 \mathrm{mo} \geq 10 \mathrm{y}$ older & 5.5 \\
\hline Age at sexual debut $\leq 14$ y & 7.8 \\
\hline Did not talk to most recent partner in past 12 mo about using condoms & 20.5 \\
\hline Mean condom use self-efficacy (low 0 , high 3 ) & 2.36 \\
\hline Perceive self to be at high risk for HIV infection & 38.4 \\
\hline Ever been tested for HIV & 32.6 \\
\hline Know HIV status & 18.9 \\
\hline Had sex $>5$ times in past month & 10.0 \\
\hline Reported unusual vaginal discharge in the past 12 months & 19.2 \\
\hline Ever pregnant & 49.5 \\
\hline Age $20-24$ y & 64.1 \\
\hline Did not complete high school & 72.9 \\
\hline Live in a rural area & 47.3 \\
\hline Married & 4.3 \\
\hline Religion not important in everyday life & 13.7 \\
\hline Black African & 88.4 \\
\hline
\end{tabular}

\section{Results}

HIV prevalence in our sample was $21 \%$. Most women (71\%) reported inconsistent condom use, and $12.8 \%$ reported having had more than one sexual partner in the past 12 months. Almost 27\% reported low relationship control, and nearly $4 \%$ reported that they had been physically forced to have sex by their most recent partner (just under $10 \%$ reported ever having been physically forced to have sex). Approximately 50\% of women reported ever having been pregnant, and $19.2 \%$ reported having had an unusual vaginal discharge in the past 12 months. Almost $19 \%$ of women reported knowing their HIV status. Other information on the sociodemographic characteristics and HIV risk behaviors of the sample is presented in Table 1.

\section{Bivariate Analyses}

No significant association was found between low relationship control and HIV infection in bivariate analyses comparing women who were HIV infected to those who were not $(24.1 \%$ vs. 28.3\%, p $=0.31)$ (Table 2). Additionally, no association was found between the woman's experience of forced sex with her most recent partner and HIV serostatus (3.6\% vs. 3.9\%, p $=0.82$ ). Women who were HIV seropositive were significantly more likely to have had more than one lifetime sexual partner, to be 20-24 years of age, to have not completed high school, to be of black African race, and to be single. HIV- positive women were also significantly more likely to be inconsistent condom users $(78.7 \%$ vs. $69.6 \%, \mathrm{p}=0.01)$. No significant associations were found between HIV and recent experience of transactional sex, having an older partner, or young age at coital debut.

As we had hypothesized, inconsistent condom users were significantly more likely to report low relationship control (33.4\% vs. $13.5 \%, \mathrm{p}<0.001)$ and to have been forced to have sex by their most recent partner ( $5 \%$ vs. $1 \%$, $\mathrm{p}<0.001$ ) when consistent condom users were compared with inconsistent condom users in bivariate analyses (Table 3). Further, inconsistent condom users were more likely to have low condom use self-efficacy, to be in relationships with older partners, to have frequent sex with their partner, not to have discussed condoms with their partner, to be married, to have experienced early sexual debut, not to have completed high school, to perceive themselves as being at high risk for HIV infection, and to be in the older age group (20-24 years).

\section{Multivariate Analyses}

No direct association was seen between our two sexual power measures (relationship control and forced sex) and HIV infection in the logistic regression model (Table 4). Inconsistent condom users were significantly more likely to be infected with HIV (odds ratio [OR] 1.58, 95\% confidence interval [CI] 1.10-2.27). The odds of HIV infection 
Table 2. Weighted frequencies and results of chi-square tests for relationship control factors, HIV risk behavior, and sociodemographic factors by HIV status among sexually experienced women 15-24 years of age, South Africa, $2003^{a}$

\begin{tabular}{|c|c|c|c|}
\hline Characteristic & HIV negative $(78.9 \%)$ & HIV positive (21.1\%) & Chi-square $\mathrm{p}$ value \\
\hline High relationship control (score 0-2) with current partner & 71.7 & 75.9 & 0.31 \\
\hline Low relationship control (score $3-4$ ) with current partner & 28.3 & 24.1 & \\
\hline Last partner in past 12 mo forced to have sex & 3.9 & 3.6 & 0.82 \\
\hline Last partner in past 12 mo did not force to have sex & 96.1 & 96.4 & \\
\hline Mean condom use self-efficacy score $(0 \text { low to } 3 \text { high })^{b}$ & 2.35 & 2.38 & 0.68 \\
\hline Transactional sex with last partner in past 12 mo & 1.3 & 1.5 & 0.89 \\
\hline No transactional sex with last partner in past $12 \mathrm{mo}$ & 98.7 & 98.5 & \\
\hline Last partner in past $12 \mathrm{mo} \geq 10 \mathrm{y}$ older & 5.1 & 7.5 & 0.08 \\
\hline Last partner in past $12 \mathrm{mo}<10 \mathrm{y}$ older & 94.9 & 92.5 & \\
\hline Did not always use a condom with last partner in past $12 \mathrm{mo}$ & 69.6 & 78.7 & 0.01 \\
\hline Always used a condom with last partner in past $12 \mathrm{mo}$ & 30.4 & 21.3 & \\
\hline Age at sexual debut $\leq 14 \mathrm{y}$ & 7.8 & 7.7 & 0.93 \\
\hline Age at sexual debut $>14 \mathrm{y}$ & 92.2 & 92.3 & \\
\hline$>1$ lifetime sexual partners & 51.1 & 67.7 & 0.03 \\
\hline 1 lifetime sexual partner & 48.9 & 32.4 & \\
\hline Sex in past month with last partner in past $12 \mathrm{mo} \leq 5$ & 90.3 & 89.1 & 0.49 \\
\hline Sex in past month with last partner in past $12 \mathrm{mo}>5$ & 9.7 & 10.9 & \\
\hline Talked about condom use with last partner in past $12 \mathrm{mo}$ & 80.2 & 76.4 & 0.24 \\
\hline Did not talk about condom use with last partner in past 12 mo & 19.8 & 23.6 & \\
\hline Perceive self to be at high risk for HIV infection & 38.3 & 39.0 & 0.89 \\
\hline Perceive self to be at low or no risk for HIV infection & 61.7 & 61.0 & \\
\hline Age $15-19$ y & 40.4 & 19.0 & $<0.001$ \\
\hline Age 20-24 y & 59.6 & 81.0 & \\
\hline Completed high school & 29.3 & 18.7 & $<0.001$ \\
\hline Did not complete high school & 70.7 & 81.3 & \\
\hline Live in a rural area & 48.6 & 42.6 & 0.14 \\
\hline Live in an urban area & 51.4 & 57.4 & \\
\hline Race Black African & 85.9 & 97.9 & $<0.001$ \\
\hline Other race & 14.1 & 2.1 & \\
\hline Religion very important in everyday life & 86.5 & 85.9 & 0.8 \\
\hline Religion not very important in everyday life & 13.5 & 14.1 & \\
\hline Married & 4.9 & 2.3 & 0.002 \\
\hline Single & 95.1 & 97.7 & \\
\hline
\end{tabular}

'Source: National Survey of HIV and Sexual Risk Behavior among Young People Age 15-24, South Africa, 2003.

${ }^{b} t$ test for differences between means (tested with the lincom command in STATA for svymeans).

were 2.49 times greater among women with more than one lifetime sexual partner (OR 2.49, 95\% CI 1.80-3.43) than among those with one partner. Women who were older (ages 20-24 years), were single, did not complete high school, lived in an urban area, and were of Black African race were also significantly more likely to be infected with HIV.

Relationship control and recent experience of forced sex were significantly associated with condom use consistency in logistic regression models (Table 5). Women who reported low relationship control were 2.10 times more likely to be inconsistent condom users (OR 2.10, 95\% CI 1.17-3.78). Forced sex was found to exert particularly strong effects on inconsistent condom use: women who reported that their most recent partner forced them to have sex were 5.77 times more likely to be inconsistent condom users with that partner (OR 5.77, 95\% CI 1.86-17.91). Women who reported low condom use self-efficacy were also at increased risk of inconsistent condom use: each one-point decrease in condom use self-efficacy increased the odds of inconsistent condom use by 1.86 (95\% CI 1.42-2.45). The strongest predictor of inconsistent condom use was not having talked to the most recent partner about using condoms (OR 12.86, 95\% CI 5.83-28.47). Married women, women who reported having frequent sex, older women (ages 20-24 years), and women who perceived themselves to be at high risk for HIV infection were also significantly more likely to report inconsistent condom use. Early coital debut, more than one lifetime sexual partner, and having an older partner were not found to be statistically significant predictors of condom use consistency. 
Table 3. Weighted frequencies and $\mathrm{p}$ values for relationship control factors, HIV status and risk behavior, and sociodemographic factors by condom use consistency with most recent sexual partner in past 12 months among sexually experienced women 15-24 years of age, South Africa, 2003

\begin{tabular}{|c|c|c|c|}
\hline Characteristic & $\begin{array}{l}\text { Always used condom } \\
\text { with last partner in } \\
\text { past } 12 \text { mo }(28.6 \%)\end{array}$ & $\begin{array}{l}\text { Did not always use } \\
\text { condom with last partner } \\
\text { in past } 12 \text { mo }(71.4 \%)\end{array}$ & $\begin{array}{l}\text { Chi-square } \\
\text { p value }\end{array}$ \\
\hline $\begin{array}{l}\text { High relationship control (score 0-2) with current partner } \\
\text { Low relationship control (score 3-4) with current partner }\end{array}$ & $\begin{array}{l}86.5 \\
13.5\end{array}$ & $\begin{array}{l}66.6 \\
33.4\end{array}$ & $<0.001$ \\
\hline $\begin{array}{l}\text { Last partner in past } 12 \mathrm{mo} \text { forced to have sex } \\
\text { Last partner in past } 12 \mathrm{mo} \text { did not force to have sex }\end{array}$ & $\begin{array}{c}1.0 \\
99.0\end{array}$ & $\begin{array}{c}5.0 \\
95.0\end{array}$ & $<0.001$ \\
\hline Mean condom use self-efficacy score (0 low-3 high $)^{b}$ & 2.68 & 2.16 & $<0.001$ \\
\hline $\begin{array}{l}\text { Transactional sex with last partner in past } 12 \text { mo } \\
\text { No transactional sex with last partner in past } 12 \text { mo }\end{array}$ & $\begin{array}{c}1.1 \\
98.9\end{array}$ & $\begin{array}{c}1.5 \\
98.5\end{array}$ & 0.6 \\
\hline $\begin{array}{l}\text { Last partner in past } 12 \mathrm{mo} \geq 10 \mathrm{y} \text { older } \\
\text { Last partner in past } 12 \mathrm{mo}<10 \mathrm{y} \text { older }\end{array}$ & $\begin{array}{c}3.2 \\
96.8\end{array}$ & $\begin{array}{c}6.5 \\
93.5\end{array}$ & 0.01 \\
\hline $\begin{array}{l}\text { Age at sexual debut } \leq 14 y \\
\text { Age at sexual debut }>14 y\end{array}$ & $\begin{array}{c}4.0 \\
96.0\end{array}$ & $\begin{array}{c}8.4 \\
91.6\end{array}$ & 0.001 \\
\hline $\begin{array}{l}>1 \text { lifetime sexual partners } \\
1 \text { lifetime sexual partner }\end{array}$ & $\begin{array}{l}47.7 \\
52.3\end{array}$ & $\begin{array}{l}41.7 \\
58.3\end{array}$ & 0.23 \\
\hline $\begin{array}{l}\text { Sex in past month with last partner in past } 12 \mathrm{mo} \leq 5 \\
\text { Sex in past month with last partner in past } 12 \mathrm{mo}>5\end{array}$ & $\begin{array}{c}96.4 \\
3.6\end{array}$ & $\begin{array}{l}87.5 \\
12.5\end{array}$ & $<0.001$ \\
\hline $\begin{array}{l}\text { Talked about condom use with last partner in past } 12 \mathrm{mo} \\
\text { Did not talk about condom use with last partner in past } 12 \mathrm{mo}\end{array}$ & $\begin{array}{l}98.0 \\
2.0\end{array}$ & $\begin{array}{l}72.1 \\
27.9\end{array}$ & $<0.001$ \\
\hline $\begin{array}{l}\text { Perceive self to be at high risk for HIV infection } \\
\text { Perceive self to be at low or no risk for HIV infection }\end{array}$ & $\begin{array}{l}30.0 \\
70.0\end{array}$ & $\begin{array}{l}43.3 \\
56.7\end{array}$ & $<0.001$ \\
\hline $\begin{array}{l}\text { Age } 15-19 \text { y } \\
\text { Age } 20-24 \text { y }\end{array}$ & $\begin{array}{l}54.0 \\
46.0\end{array}$ & $\begin{array}{l}33.6 \\
66.4\end{array}$ & $<0.001$ \\
\hline $\begin{array}{l}\text { Completed high school } \\
\text { Did not complete high school }\end{array}$ & $\begin{array}{l}34.5 \\
65.5\end{array}$ & $\begin{array}{l}24.1 \\
75.9\end{array}$ & 0.01 \\
\hline $\begin{array}{l}\text { Live in a rural area } \\
\text { Live in an urban area }\end{array}$ & $\begin{array}{l}38.2 \\
61.8\end{array}$ & $\begin{array}{l}51.2 \\
48.8\end{array}$ & 0.09 \\
\hline $\begin{array}{l}\text { Race Black African } \\
\text { Other race }\end{array}$ & $\begin{array}{c}90.9 \\
9.1\end{array}$ & $\begin{array}{l}88.6 \\
11.4\end{array}$ & 0.23 \\
\hline $\begin{array}{l}\text { Religion very important in everyday life } \\
\text { Religion not very important in everyday life }\end{array}$ & $\begin{array}{l}88.7 \\
11.3\end{array}$ & $\begin{array}{l}84.4 \\
15.6\end{array}$ & 0.12 \\
\hline $\begin{array}{l}\text { Married } \\
\text { Single }\end{array}$ & $\begin{array}{c}0.6 \\
99.4\end{array}$ & $\begin{array}{c}6.5 \\
93.5\end{array}$ & $<0.001$ \\
\hline
\end{tabular}

Source: National Survey of HIV and Sexual Risk Behavior among Young People Age 15-24, South Africa, 2003. ${ }^{b} t$ test for differences between means (tested using the lincom command in STATA for svymeans).

\section{Discussion}

Lack of power in sexual relationships has been hypothesized to increase women's risk of HIV infection $(3,4,19,28,29)$, but little research has shed rigorous light on this question. In this nationally representative survey, women reporting limited sexual power were not more likely to be infected with HIV. Sexual power was, however, associated with inconsistent condom use, which, in turn, was significantly associated with HIV infection.

We hypothesized that limited sexual power would increase a woman's risk of HIV infection, primarily by compromising her ability to use condoms. Women with low relationship control were significantly more likely to report inconsistent condom use (OR 2.10, 95\% CI 1.17-3.78), which is consistent with the findings of other studies $(25,30)$. This finding suggests that efforts to promote consistent condom use, a key element of HIV prevention, would benefit from efforts to enhance women's sexual power. Such efforts should not target women alone; rather, they should target and involve men as partners, essential stakeholders in improving women's sexual decision-making power.

Women reporting forced sex with their most recent sexual partner were also significantly less likely to report consistent condom use (OR 5.77, 95\% CI 1.86-17.91). While only $4 \%$ of our sample reported that their most recent partner had physically forced them to have sex, approximately $10 \%$ of all women reported having experienced forced sex. Since many women may be reluctant to disclose this information in a household survey, this figure is likely to be an 
Table 4. Adjusted odds ratios (AOR), $95 \%$ confidence intervals (Cl), and chi-square p values for HIV infection among sexually experienced women 15-24 years of age, South Africa, 2003 ${ }^{\mathrm{a}}$

\begin{tabular}{|c|c|c|}
\hline Characteristic & $\mathrm{AOR}(95 \% \mathrm{Cl})$ & Chi-square p-value \\
\hline Age $20-24$ y (vs. $15-19$ y) & $2.53(1.85-3.46)$ & $<0.001$ \\
\hline Single (vs. married) & $2.06(1.14-3.71)$ & 0.02 \\
\hline Did not complete high school (vs. completed high school) & $2.60(1.87-3.61)$ & $<0.001$ \\
\hline Live in an urban area (vs. live in a rural area) & $2.36(1.55-3.59)$ & $<0.001$ \\
\hline Black African race (vs. other race) & $7.63(3.41-17.07)$ & $<0.001$ \\
\hline $\begin{array}{l}\text { Did not always use a condom with last partner in past } 12 \text { mo } \\
\text { (vs. always used a condom) }\end{array}$ & $1.58(1.10-2.27)$ & 0.01 \\
\hline$>1$ lifetime sexual partner (vs. 1 lifetime partner) & $2.49(1.80-3.43)$ & $<0.001$ \\
\hline Last partner in past $12 \mathrm{mo} \geq 10 \mathrm{y}$ older (vs. $<10 \mathrm{y}$ older) & $1.43(0.88-2.32)$ & 0.15 \\
\hline Age of first sex $\leq 14$ y (vs. $>14$ y) & $1.12(0.67-1.87)$ & 0.66 \\
\hline $\begin{array}{l}\text { Transactional sex with last partner in past } 12 \text { mo } \\
\text { (vs. never transactional sex with last partner) }\end{array}$ & $2.03(0.53-7.77)$ & 0.30 \\
\hline Sex $>5$ times in past mo with last partner in past 12 mo (vs. $<5$ times) & $1.07(0.72-1.58)$ & 0.73 \\
\hline Last partner in past 12 mo forced to have sex (vs. did not force) & $0.82(0.45-1.52)$ & 0.55 \\
\hline Low relationship control (vs. high control) & $1.00(0.72-1.39)$ & 0.99 \\
\hline
\end{tabular}

underestimate (31). In the context of masculine norms defined by male control over sexual decision-making and prevalent forced and coercive sex, many women do not have the right of refusal $(6,8,10,32)$. In addition, our measure of physically forced sex captures only a narrow element of coercive or nonconsensual sex, which actually occurs on a continuum ranging from persuasion and trickery to force and rape $(6,31)$.

As hypothesized, inconsistent condom users were significantly more likely to be HIV-positive (OR 1.58, 95\% CI 1.10-2.26). Although this finding supports previous research on the effectiveness of consistent condom use to prevent HIV infection (33), our cross-sectional design renders it impossible to assess whether or not HIV was acquired when condom use consistency was assessed. Also possible is that the relationship operates in the opposite direction, i.e., that HIV seropositivity influences condom use consistency among persons aware of their status.
Given, however, that consistent condom use is protective against HIV, the fact that fewer than one third of women reported consistent condom use indicates that most are at risk for future infection.

We did not find a direct association between our measures of sexual power and HIV infection, which suggests that the primary mechanism through which sexual power exerts effects on HIV risk is condom use consistency. Nevertheless, this preliminary analysis considered a limited subset of sexual power measures. As such, we cannot be certain that we captured the scope and dimensions of sexual power that have a bearing on HIV risk in ways other than through consistent condom use. Recent research conducted among antenatal clinic attendees who accepted routine HIV testing in Soweto adapted and validated the SRPS, including 12 items, for use in that context. Measured in this way, sexual relationship power was found to be associated with prevalent HIV infection

\begin{tabular}{|c|c|c|}
\hline Characteristic & $\operatorname{AOR}(95 \% \mathrm{Cl})$ & Chi-square p-value \\
\hline Age $20-24$ y (vs. $15-19$ y) & $1.87(1.32-2.66)$ & $<0.001$ \\
\hline Married (vs. single) & $5.43(2.06-14.34)$ & 0.001 \\
\hline Did not complete high school (vs. completed high school) & $1.28(0.87-1.88)$ & 0.2 \\
\hline Live in rural area (vs. live in an urban area) & $1.25(0.76-2.06)$ & 0.37 \\
\hline Other race (vs. Black African race) & $1.66(1.01-2.73)$ & 0.04 \\
\hline Perceive self to be at high risk for HIV (vs. low to no risk) & $1.55(1.13-2.11)$ & 0.006 \\
\hline Low relationship control (vs. high control) & $2.10(1.17-3.78)$ & 0.013 \\
\hline Last partner in past 12 mo forced to have sex (vs. did not force) & $5.77(1.86-17.91)$ & 0.002 \\
\hline Condom use self-efficacy ( 0 high to 3 low) & $1.86(1.42-2.45)$ & $<0.001$ \\
\hline $\begin{array}{l}\text { Did not talk to last partner in past } 12 \text { mo about using condoms } \\
\text { (vs. did talk about using condoms) }\end{array}$ & $12.86(5.83-28.47)$ & $<0.001$ \\
\hline$>1$ lifetime sexual partner (vs. 1 lifetime partner) & $1.22(0.72-2.06)$ & 0.45 \\
\hline Last partner in past $12 \mathrm{mo} \geq 10 \mathrm{y}$ older (vs. $<10 \mathrm{y}$ older) & $1.11(0.56-2.20)$ & 0.75 \\
\hline Age at first sexual experience $\leq 14$ y (vs. $>14$ y) & $1.62(0.97-2.73)$ & 0.06 \\
\hline Sex $>5$ times in past month with last partner in past $12 \mathrm{mo}$ (vs. 0 times) & $2.85(1.69-4.79)$ & $<0.001$ \\
\hline
\end{tabular}

${ }^{2}$ Source: National Survey of HIV and Sexual Risk Behavior among Young People Age 15-24, South Africa, 2003. 
(OR 1.53, 95\% CI 1.10-2.04) (34); however, the authors did not control for condom use in their analysis, which may account for their findings. Associations between power and sexual behavior are likely to depend on sample characteristics, the conceptualization and measurement of power and risk behaviors, or a combination of these factors (35). Our nationally representative sample included young women from multiple regions, races, and cultures, among which key elements of sexual power dynamics are likely to differ.

The inherent limitations of our cross-sectional study design and the fact that we measured HIV prevalence, rather than incidence, may help explain the lack of an association between sexual power and HIV infection. The measures of sexual power described here refer to recent events in a current partnership, while infection may have been acquired in a prior partnership or under a different dynamic in the current partnership. We attempted to correct for this limitation by conducting a subanalysis among women 15-19 years of age with only one lifetime sex partner, who would likely have acquired HIV in the current partnership. Relationship control and HIV infection remained unassociated in this subanalysis (OR 0.98; 95\% CI 0.76-1.26) ${ }^{1}$. Women who reported that their most recent partner forced them to have sex were at increased risk of HIV infection, but this association was not significant (OR 1.44; 95\% CI 0.33-6.34).

Woman's sexual negotiating power is likely to be compromised in transactional sexual relationships, in relationships with older partners, and following early coital debut (28), and these factors would be expected to influence both condom use consistency and HIV risk. In this survey, the self-reported prevalence of all three of these behaviors was low: only $1.3 \%$ of women reported that they had transactional sex with their most recent partner; $5.5 \%$ reported that their most recent partner was >10 years older; and $7.8 \%$ reported having had sex at age 14 or younger. Transactional sex and early coital debut are particularly likely to be subject to underreporting due to social desirability bias. Further, young women whose first sexual encounter is nonconsensual, which is fairly common in this context (8), may not define it as "coital debut." All three of these variables were associated with increased risk of HIV infection, although the associations were not significant. Transactional sex was not associated with condom use consistency in this study. Women who reported older partners and early first sexual experience were more likely to report inconsistent condom use, though this difference was not statistically significant.

The strongest risk factor for not always using condoms with the most recent sexual partner was not having talked to that partner about condom use (OR 12.91, 95\% CI 5.85-28.51). Communication between partners about con- traceptive use, including condoms, has been shown to be associated with consistent use in other studies (29). In the context of our cross-sectional study, confirming the direction of the relationship is not possible: although couples who discuss condoms may be more likely to use them, those who consistently use condoms may also be more likely to discuss them. Sexual power may have an effect on partner communication and should be explored further in future research.

Given the associations between sexual power and condom use consistency, more research is warranted to assess the determinants of sexual negotiating power and to test the effectiveness of gender-sensitive HIV prevention interventions. A large national HIV prevention campaign for youth in South Africa, loveLife, has incorporated gender power issues into its media campaign by addressing issues of transactional sex, older partners, and women's lack of decision-making power in relationships (www.lovelife. org.za) (Figure). The Stepping Stones package, which is used by Planned Parenthood South Africa, also aims to challenge gender norms (32) and was recently found to increase women's sexual power in a pilot evaluation (36).

A small but growing body of research suggests that economic empowerment strategies may improve women's sexual power, with potential health benefits. In Gabarone, Botswana, economic independence was more strongly related to women's negotiating power in relationships than any other variable explored (19), and in Zimbabwe, adolescents who had their own income were significantly more likely to be consistent condom users (Megan Dunbar, pers. comm.). In the Limpopo province of South Africa, the Intervention with Micro-finance for AIDS and Gender Equity (IMAGE) program is being evaluated to determine its effect on gender-based violence, sexual behavior, and HIV incidence (37). The intervention combines a micro-finance program with a participatory learning and action curriculum. In collaboration with local partners, the University of California-San Francisco Department of Obstetrics, Gynecology, and Reproductive Sciences is currently engaged in a multisite program of research to further elucidate the linkages among economic power, sexual negotiating power, and sexually transmitted infection (STI) outcomes and to develop and test related interventions.

Debate centers around the relative effectiveness of each of the "ABCs" of HIV prevention: abstinence, being faithful to one partner, and condom use (38). However, all three elements likely play a role. Indeed, a decontextualized focus on these elements is likely to fail. HIV prevention strategies

${ }^{1}$ Note that relationship control was used as a continuous variable in this model as it had a more coherent relationship with HIV than did the categorical version. 


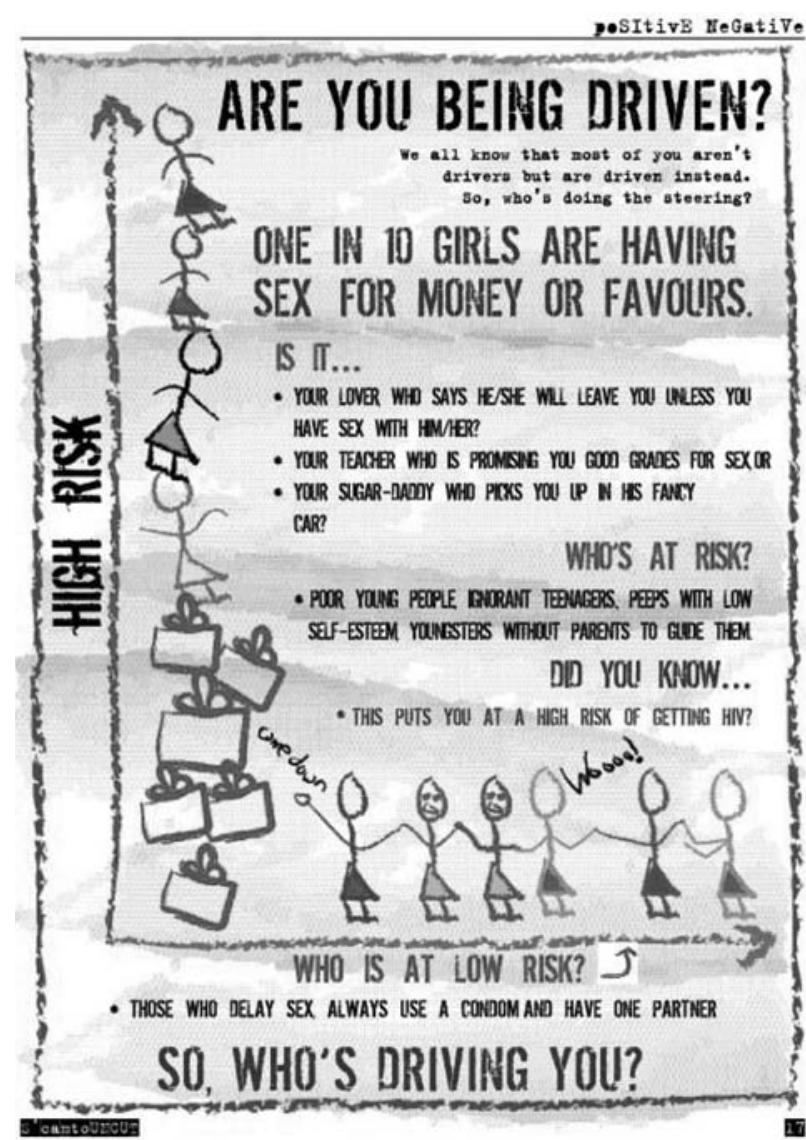

Figure. Example of message from loveLife's HIV prevention program in South Africa.

must take full account of the barriers persons, particularly women, face in bringing about behavior changes over which they may have little control. Many of these barriers are rooted fundamentally in gender inequalities.

\section{Conclusion}

For a number of years, HIV activists and researchers have highlighted the role gender inequality may play in placing women at increased risk for HIV infection. At the recent International AIDS Conference in Bangkok, United Nations Secretary-General Kofi Annan made the empowerment of women and girls a priority focus area for HIV prevention: "No less pressing, empowering women and girls to protect themselves against the virus.... What is needed is positive change that will give more power and confidence to women and girls. Change that will transform relations between women and men at all levels of society." While empiric evidence documenting the relationship between women's sexual power and their HIV risk has been in short supply, a small but growing body of research confirms that women's lack of power in relationships com- promises their sexual health. While this exploratory study did not find an association between sexual power and HIV serostatus, it did confirm an association between two measures of sexual power, relationship control and forced sex, and condom use consistency. Further work is needed to refine and apply measures of sexual power and to assess the complex relationship between sexual power and HIV susceptibility in the South African context. Additional research should also aim to elucidate the underpinnings of sexual power, with a particular focus on identifying avenues for intervention.

\section{Acknowledgments}

We thank Julie Pulerwitz for her contribution to our formative analytic ideas and the evaluation team at the Reproductive Health Research Unit, University of the Witwatersrand, South Africa, and Development Research Africa, which helped collect the data used in this analysis.

The study from which the data for this analysis were derived was funded by the Kaiser Family Foundation. The views expressed in this article do not necessarily reflect those of the funder.

Dr. Pettifor is research director of the Adolescent Health Research Programme at the Reproductive Health Research Unit, University of the Witwatersrand, South Africa. Her research interests include gender differences in HIV risk factors among adolescents, female-controlled barrier methods, STI treatment, and the role of STIs in HIV infection.

\section{References}

1. Summary report national HIV and syphilis. Antental seroprevalence survey in South Africa, 2002. Pretoria: South African Department of Health; 2003.

2. Shisana O, Simbayi L. Nelson Mandela/HSRC Study of HIV/AIDS South African national HIV prevalence, behavioural risks and mass media household survey 2002. Cape Town: Human Sciences Research Council; 2002.

3. Gender and HIV/AIDS: taking stock of research and programs. Geneva: UNAIDS; 1999.

4. Weiss E, Whelan D, Gupta G. Gender, sexuality and HIV: making a difference in the lives of young women in developing countries. Sexual and Relationship Therapy. 2000;15:233-45.

5. Gilbert L, Walker L. Treading the path of least resistance: HIV/AIDS and social inequalities - a South African case study. Soc Sci Med. 2002;54:1093-110.

6. Wood K, Jewkes R. 'Dangerous’ love: reflections on violence among Xhosa township youth. In: Morrell R, editor. Changing men in southern Africa. Pietermaritzburg: University of Natal Press; 2001. p. 317-36.

7. Varga C. Sexual decision-making and negotiation in the midst of AIDS: youth in KwaZulu-Natal South Africa. Health Transit Rev. 1997;7(Suppl 3):45-67.

8. Wood K, Maforah F, Jewkes R. "He force me to love him”: putting violence on adolescent sexual health agendas. Soc Sci Med. 1998;47:233-42. 
9. MacPhail C, Campbell C. 'I think condoms are good but, aai, I hate those things': condom use among adolescents and young people in a southern African township. Soc Sci Med. 2001;52:1613-27.

10. Varga C. How gender roles influence sexual and reproductive health among South African adolescents. Stud Fam Plann. 2003;34:160-72.

11. Swart-Kruger J, Richter L. AIDS-related knowledge, attitudes and behavior among South African street youth: reflections on power, sexuality and the autonomous self. Soc Sci Med. 1997;45:957-66.

12. MacPhail C, William B, Campbell C. Relative risk of HIV infection among young men and women in a South African township. Int J STD AIDS. 2002;13:331-42.

13. Kaufman CE, Stavrou SE. "Bus fare, please": The economics of sex and gifts among adolescents in urban South Africa. Policy Research Division Working Papers: Population Council; 2002.

14. Gage A. Women's socioeconomic position and contraceptive behavior in Togo. Stud Fam Plann. 1995;26:264-77.

15. Hindin M. Women's autonomy, women's status and fertility-related behavior in Zimbabwe. Popul Res Policy Rev. 2000;19:255-82.

16. Hogan D, Berhanu B, Hailemariam A. Household organization, women's autonomy, and contraceptive behavior in southern Ethiopia. Stud Fam Plann. 1999;30:302-14.

17. Kritz M, Makinwa-Adebusoye P, Gurak D. The role of gender context in shaping reproductive behaviour in Nigeria. In: Presser H, Sen G, editors. Women's empowerment and demographic processes: moving beyond Cairo. Oxford: Oxford University Press; 2000. p. 239-60.

18. Laban E, Gwako M. Conjugal power in rural Kenya families: its influence on women's decisions about family size and family planning practices. Sex Roles. 1997;36:127-48.

19. Greig F, Koopman C. Multilevel analysis of women's empowerment and HIV prevention: quantitative survey results from a preliminary study in Botswana. AIDS Behav. 2003;7:195-208.

20. Blanc AK, Wolff B. Gender and decision-making over condom use in two districts in Uganda. Afr J Reprod Health. 2001;5:15-28.

21. Gutierrez L, Oh H, Gillmore M. Towards an understanding of (em)power(ment) for HIV/AIDS prevention with adolescent women. Sex Roles. 2000;42:581-611.

22. Harvey SM, Beckman LJ, Browner CH, Sherman CA. Relationship power, decision making, and sexual relations: an exploratory study with couples of Mexican origin. J Sex Res. 2002;39:284-91.

23. Bowleg L, Belgrave F, Reisen C. Gender roles, power strategies, and precautionary self-efficacy: implications for black and Latina women's HIV/AIDS protective behaviors. Sex Roles. 2000;42:613-35.

24. Wingood G, DiClemente R. Pattern influences and gender-related factors associated with noncondom use among young adult African American women. Am J Community Psychol. 1998;26:29-53.

25. Pulerwitz J, Amaro H, De Jong W, Gortmaker SL, Rudd R. Relationship power, condom use and HIV risk among women in the USA. AIDS Care. 2002;14:789-800.

26. Pettifor A, Rees H, Steffenson A, Hlongwa-Madikizela L, MacPhail C, Vermaak K, et al. HIV and sexual behaviour among young South Africans: a national survey of 15-24 year olds. Johannesburg: Reproductive Health Research Unit, University of the Witwatersrand; 2004. [cited 2004 Feb]. Available from http://www.rhru.co.za/ images/Docs/Fact\%20Sheet.pdf
27. Pulerwitz J, Gortmaker SL, De Jong W. Measuring sexual relationship power in HIV/STD research. Sex Roles. 2000;42:637-60.

28. Laga M, Schwartlander B, Pisani E, Salif Sow P, Carael M. To stem HIV in Africa, prevent transmission to young women. AIDS. 2001;15:931-4.

29. Blanc AK. The effect of power in sexual relationships on sexual and reproductive health: an examination of the evidence. Stud Fam Plann. 2001;32:189-213.

30. Jewkes RK, Nduna M, Jama PN, Levin JB. Measuring relationship power: adaptation of the SRPS for South Africa. In: Abstracts of the XIV International AIDS Conference; Barcelona, Spain; 2002 Jul 7-12; Abstract code WeOrD1353. Available from http://www.ias.se/ abstract/show.asp?abstract_id $=4486$

31. Jewkes R, Levin J, Penn-Kekana L. Risk factors for domestic violence: findings from a South African cross-sectional study. Soc Sci Med. 2002;55:1603-17.

32. Jewkes R, Abrahams N. The epidemiology of rape and sexual coercion in South Africa: an overview. Soc Sci Med. 2002;55:1231-44.

33. Ahmed S, Lutalo T, Wawer M, Serwadda D, Sewankambo N, Nalugoda F, et al. HIV incidence and sexually transmitted disease prevalence associated with condom use: a population study in Rakai, Uganda. AIDS. 2001;15:2171-9.

34. Dunkle K, Jewkes R, Brown H, Gray G, McIntyre J, Harlow S. Gender-based violence, relationship power, and risk of prevalent HIV infection in women attending antenatal clinics in Soweto, South Africa. Lancet. 2004;363:1415-21.

35. Sionean C, DiClemente RJ, Wingood GM, Crosby R, Cobb BK, Harrington K, et al. Psychosocial and behavioral correlates of refusing unwanted sex among African-American adolescent females. J Adolesc Health. 2002;30:55-63.

36. Nduna M, Jewkes R, Jama P, Levin J. Results from the pilot evaluation of stepping stones. In: Abstracts of the XIV International AIDS Conference; Barcelona, Spain; 2002 Jul 7-12; Abstract code WePeD6298. [cited 2004 Feb]. Available from http://www.ias.se/abstract/show.asp?abstract_id=6817

37. Hargreaves J, Gear J, Kim J, Mzamani B, Makhubele M, Mashaba K, et al. Social interventions for HIV/AIDS Intervention with Microfinance for AIDS and Gender Equity, IMAGE study evaluation monograph no. 1. Acornhoek, South Africa: Rural AIDS and Development Action Research Program, London School of Hygiene and Tropical Medicine; 2002.

38. Shelton J, Halperin D, Nantulya V, Potts M, Gayle H, Holmes KK. Partner reduction is crucial for balanced “ABC” approach to HIV prevention. BMJ. 2004;328:891-4.

Address for correspondence: Audrey Pettifor, Reproductive Health Research Unit, Department of Obstetrics and Gynecology, Chris Hani Bagawanath Hospital, P.O. Bertsham 2013, Soweto, South Africa; fax: 27-11-933-1227; email: a.pettifor@rhrujhb.co.za

The opinions expressed by authors contributing to this journal do not necessarily reflect the opinions of the Centers for Disease Control and Prevention or the institutions with which the authors are affiliated.

\section{emerging infectious diseAses OMline}

\section{WWW.cdc.gov/eid}

To receive tables of contents of new issues send an email to listserve@cdc.gov with subscribe eid-toc in the body of your message. 